Original Research

\title{
The Impact of Preceptorship Program on Turnover Intention of Fresh Graduate Nurses in Hospital
}

\author{
Vera Rodessa ${ }^{1 *}$, Anwar Kurniadi $^{2}$, \& Agustinus Bandur ${ }^{3}$ \\ ${ }^{1}$ STIK Sint Carolus, Jakarta, Indonesia \\ ${ }^{2}$ Universitas Pertahanan, Bogor, Indonesia \\ ${ }^{3}$ Universitas Bina Nusantara, Jakarta, Indonesia
}

\begin{tabular}{|c|c|}
\hline Article Info & Abstract \\
\hline $\begin{array}{l}\text { Article history: } \\
\text { Received: } \\
10 \text { September } 2020 \\
\text { Accepted: } \\
18 \text { November } 2020\end{array}$ & $\begin{array}{l}\text { Introduction: The transition period in the first year of nursing career is a } \\
\text { difficult time for new nurses to adapt. The transition process for a new } \\
\text { nurse is known as the Duchscher's transition shock model. Almost all } \\
\text { hospitals worldwide have experienced difficulties with regards to the } \\
\text { ability of new nurses to adapt to profession. The Preceptorship is a } \\
\text { program designed to help new nurses adapt during the transition. This }\end{array}$ \\
\hline $\begin{array}{l}\text { Keywords: } \\
\text { transition shock, } \\
\text { adaptation, } \\
\text { acceptance, fresh } \\
\text { graduate, } \\
\text { resignation }\end{array}$ & $\begin{array}{l}\text { study aims primarily at exploring the impacts of the program to the } \\
\text { turnover intention of fresh graduate nurses working in hospital. } \\
\text { Methods: For this major purpose, a qualitative research with particular } \\
\text { reference to phenomenology design was applied. Accordingly, this } \\
\text { research applied in-depth interviews with active participation of } 13 \text { key } \\
\text { informants. The informants are fresh graduate nurses employed in two } \\
\text { private hospitals in Jakarta. } \\
\text { Results: The results of thematic and cross-case analysis with N Vivo v.12 } \\
\text { indicate four themes: preceptorship process, experiences in transition, } \\
\text { problem arising during transition period and preceptorship program in } \\
\text { helping nurse. } \\
\text { Conclusion: It is found that nurses aged } 22 \text { years old and } 7 \text { months of } \\
\text { working experience are the most likely to resign. The experience of new } \\
\text { nurses undergoing to transition period affects } 48 \% \text { of their desire to leave } \\
\text { work. This study recommends conducting further research on what kind } \\
\text { of work environment is ideal for facilitating adaptation for new nurses. }\end{array}$ \\
\hline
\end{tabular}

\footnotetext{
*Corresponding Author:

e-mail: vera.rodessa@gmail.com
}

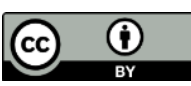

This work is licensed under a Creative Commons Attribution 4.0 International License. 


\section{INTRODUCTION}

Nursing as a professional care provider based on nursing knowledge and tips, as providing patient care oriented. Regulation of the Minister of Health of the Republic Indonesia No.49 of 2013 requires that every hospital has to ensure that every nurse who provides nursing services is a competent nurse by a Nursing committee [1].

The results of a study conducted by previous scholars, showed that $10 \%$ of new nurses in Australia wish to leave nursing. Data in Western Australia 2010-2016 indicated that $7.6 \%$ of new nurses left the program for new nurses [2]. In several international journals, it is illustrated that this problem has become an international problem, such as in the United State of America (USA) with an average of $30-50 \%$, possibly due to expectations of competence [3].

In 2016, in Taiwan, it was found that the number of nurses who worked in the first year was 28\%. Taiwan's Nursing Board reported that the turnover rate for new nurses in the first year of employment was $57.7 \%$ and it reached its peak in the first 3 months of work at $32.1 \%$. Rate for new nurses in Taiwan is 23 times higher compared to other Asian countries such as Hong Kong, Japan, Korea and Singapore [4]. Likewise, the nurses feel traumatic experiencing the real world of working as a nurse in the first year. In Canada it was found that $30 \%$ of fresh graduate nurses who graduated in the last 5 years have left their position as a nurse [5].

Fresh graduate nurses also experience feelings of dissatisfaction with the work environment, workload problems and feelings of worthlessness [6]. In Indonesia, from a qualitative study conducted on 5 students of the FKIK Unsoed Nurse Program, it was reported that professional relationships with other disciplines were felt as a separate pressure [7].

Turnover also has an impact on the cost of setting up the preceptor and decreasing the morale of the unit. It said a turnover or two could be a trigger for other nurses to leave. Turnover new nurses at HB Hospital in 2019 were 18\% -50\% and SMC Hospital 25\% - 75\% [8].

New graduate nurses need a transition period before becoming competent clinical nurses at the Hospital. Nurses who are working for the first time (fresh graduates) have difficulties during the transition from students to professional practitioners and often experience a phenomenon known as shock during the transition period [9]. He also said that Reality shock has four phases, namely phase (honeymoon), phase shock (shock), phase recovery (recovery) and phase resolution (resolution).

Duchscher's theory of the transition to shock from the results of ten years of research proves that new graduate nurses are afraid of being said to be incompetent, afraid of providing unsafe treatment, and deliberately causing harm, and afraid of not being able to cope with the responsibilities assigned to them. In the end, they are afraid of being rejected as new colleagues, where this feeling is related to the confidence level of the new nurse and personal views about the professional [10].

Preceptorship was introduced to nursing in the UK in 1991 with the aim of enhancing competence and self-confidence. Currently 
nursing education in the United Kingdom (UK) has changed from a practice-based education to a theoretical model [11], [12]. This change aims to produce workers who have confidence in evidence-based advocacy and nursing.

The reception program at HB Hospital and SMC Hospital which are in the SMC Hospital group is part of the orientation and socialization process to help the transition process from learner to practitioner, reduce the impact of reality shock and increase the confidence of new nurses so that they can provide good and competent service.

The number of new nurses who resigned during 2019 at HB Hospital was 16 out of 59 who entered (27\%) and at the hospital. SMC as many as 46 people from 61 who entered (75\%) of the interviews conducted before the new nurse left (exit interview), it was found that 5 people said that the high burden of responsibility is one of the hard things to go through while working. Buff, 1990 argued that the maximum nurse turnover was $12 \%$ per year while Gillis, 1994 stated that the maximum nurse turnover was 5-10\% per year [8].

There needs to be an adaptation for nurses who are new from education to the world of work who have a stressful workload, work environment and are not used to collaborating with other professions. Seeing the high turnover rate for new nurses in these two hospitals, which is $20-30 \%$ higher than the old nurses, the researchers wanted to know the experiences of new nurses (fresh graduates) during the transition period. Do new nurses experience the same phenomena described in Duchscher's theory of transition shock as they pass through their transition? Based on this evidence, it is hoped that an appropriate and effective program can be made to help new nurses through the transition period. In this research, the aim is to look at the experiences of new nurses undergoing a transition period, and help them adapt to prevent a high turnover rate.

\section{METHODS}

\section{Study Design}

The method used in this research is qualitative, focusing on describing and understanding fresh graduate nurse during transition period.

This study emphasizes on investigating the experiences of new nurses in going through the transition period when they first started working. Accordingly, this study applied qualitative phenomenology design which focuses on interpreting the meanings of individual experiences. Fresh graduate nurses with the criteria of working $0-12$ months, have passed the preceptorship program and have the intention to leave work. Every participant has clearly understood the information related to the background, objectives, benefits, risk and the research process. They were given the opportunity to ask questions and they are well-informed before they agree as participants.

This research applied in-depth interviews with active participation of 13 key informants. In line with the research design, data collection in this study was conducted by the researchers via interview with a duration of 30-60 minutes. The interview procedures were conducted on the basis of main open- 
ended questions and prompts used as the interview guidance.

\section{Ethical Considerations}

This study has been put through a feasibility assessment approved by ethics commission of Health Research and Development Sint Carolus College of Health Science no 044/KEPPSTIKSC/IV/2020. The principles of research ethics are confidentiality and privacy. Hence, when people are selected to be the participants of research, this is as indicated by fulfilment of the informed consent [13], [14].

\section{RESULTS}

\section{Overview by Age}

The age range in this study was 21-27 years and the most were 22 years old (30.77\%).

\section{Overview Based on the Distribution of Length of Work}

The results of the analysis show that most participants have a work period of 6 months and more, namely as many as $92,31 \%$.

\section{Themes and sub themes}

The theme of Preceptorship process have sub themes: implementation of orientation outreach, lesson obtained during preceptorship, teaching and advisory program, rotation during preceptorship program and evaluation during preceptorship program.

The theme of experiences in transition have sub themes: adapting to new roles, application in practice, response and efforts to knowledge, providing nursing care, new nurse role, collaborate with one profession and other professions, solution in troubleshooting, experience undergoing nursing practice and understanding of the nursing profession.

The theme of Problem arising during the transition period have sub themes: work environment, workload, job satisfaction and preceptorship period

The theme of the influence of preceptorship program have sub themes: knowledge and experience of the preceptor, preceptor abilities, the preceptor's teaching ability, helping through the transition period, opinions against new nurses and desiring to leave work.

\section{Participant's Statement Distribution} Scheme on Transition Period Sub-Theme Participants' statements were normally distributed to all sub-themes of the influence of the receptive program in helping nurses through the transition period, experiences through the transition period, analysis of the preceptor process and analysis of problems during the transition period.

\section{Interpretation of Data Analysis in Relation to the Preceptor Process}

Based on the results of the data analysis, each participant gave a statement regarding the question on preceptor process. The majority of statements conveyed have similarities, but there are also those with different opinions. Participants 2 and 9 had almost the same number of statements at the lowest level and participant 2 gave the least statement (1.30\%). Participants 7 and 11 have as many statements at the highest level. Participants 
who conveyed the most statements for the preceptor process were number 7 (6.50\%).

"At the first, I feels it was difficult, we were initially practicing with a Phantom, but now I am practicing care on an actual human being so I feel more nervous than before. Then there is responsibility" (Participant 1).

"I was adapting a little when I was talking to my seniors. Then realize who the person that I can cooperate with. At first one week my job, I have a lot of questions because I need to be in the same work flow as the others. I need to be able to apply what I have learnt and do my job" (Participant 12).

"At the beginning of my job here there were a couple diagnosis that I did not know and during handover I will ask a senior about it" (Participant 7).

"It's pretty good in the ward, there is no difference bet between Junior and senior. Even I was new and asked a lot of thing, the seniors don't get annoyed. So they try to help each other and support each other's shortcomings" (Participant 13).

\section{Interpretation Analysis Data Relating to Experience Transition Period}

Based on the results, all participants gave statements regarding their experiences of undergoing a transition period as a new nurse. Two participants, number 12 and 13 had similar statements regarding their experiences of undergoing the transition period, participants 6 and 7 had similar statements. Participants 8 and 9 have different opinions from other participants even though in certain cases there are some similarities. The 8th participant gave the most statements about the experience of undergoing a transition period, namely as much as $20.06 \%$. Participants who gave the least amount of statements about their experiences of undergoing a transition period were participant number 2 as much as $2 \%$.

"Yesterday I was placed in the VIP Ward, so that communication must be processed really. We are taught how to give care in the VIP ward, I'm happy ma'am, I'm happier. I think there is a lot more thing going on in the hospital, it is not only about putting patient on IV fluid, counting fluids etc. In Actuality there is a lot to that needs to be done" (Participant 1).

"When we are busy preparing a patient's medication we will suddenly be called by another patient. We will ask another one of our fellow nurses to take over the call because, we are still preparing the medication. If it is the pharmacy, we will ask them for infection or tablet medication by phone. We will say I'm sorry, but is the medication coming? of course, the way that we ask is polite. But so far team work is ok. We as nurses still need to work well with other health professional" (Participant 10).

"In the beginning there is still shyness and feeling of unreness in communicating with other health professionals. Even though I'm a new nurse, so far I have no trouble with communicating with other health professionals" (Participant 11).

"I am so nervous about making mistakes. This is a patient's life we are talking about. But I mean, I pledged before 
joining the workforce, right? From there, I have to understand what my role is so that I won't be careless and do whatever in my job" (Participant 12).

"There is a difference there needs to be a way to adapt. It's important as the bridge of becoming a person with education and professional. It depend on the person how they are trained. I am someone who is wholly prepared to go into the workforce" (Participant 3).

\section{Interpretation of Data Analysis Regarding} the Problems encountered during the Transition Period

Based on the results of the data analysis, all participants gave statements related to problems during the transition to adaptation. Participants 9 gave the least statement $(0$, $89 \%)$. The 11th participant gave a statement of benefit for the problem during the transition period $(7,78 \%)$.

"My responsibilities are much bigger when I am a full-fledged nurse than when I was a student. If there was anything that I don't know, I will ask my seniors questions or find references in books or the internet" (Participant 11).

"The first time that I got to work, I felt really happy but I remind myself to treat this job seriously. I feel burdened by the responsibility because I am working with real people and I am scared of making mistakes" (Participant 12).

"The burden wasn't too great when I first entered the workforce as $i$ was still supervised in the orientation period, my burden was heavier. I have to be responsible for my own work. It's different in comparison to when I was still a student since I was acting under supervision" (Participant 8).

\section{Interpretation of Data Analysis Regarding} the Effect of Preceptorship Program in Assisting the Transition Period

Based on the data analysis, all participants gave a statement about the effect of the receptionist program on helping new nurses to adapt. Participants 3 gave at least a statement about the effect of the preceptor program helping in adaptation (2.24\%). The 9 th participant gave the most statements $(14$, 84\%). Many participants' statements are similar and some are different.

"At first, I still needed supervising, because I'm working in an area where people often come and I don't know what kind of health condition they have. That's why I always ask questions and communicate either with my peers or other health professionals. When patients are a bit more demanding, other people from the medical team will try to hurry us up with our work, and that makes us hurry our other peers up with their work. We do our best because we are scared of making mistakes. We were trying to build up our confidence, but along the way, our confidence increased because we know what to do now" (Participant 12).

"If we're talking about the length of the preceptor ship programs, which is 3 months, I think it's too long. We should just all just go directly to the wards so we can immediately adapt to the ward" (Participant 13). 
"In my opinion, there is nothing that I can gain from the knowledge of all the seniors have here. What I have learnt in school is enough. The procedures that the seniors practice do not go along with what I have learnt in school, which is wrong. I will follow what I have learnt instead of the seniors" (Participant 2).

"A good knowledge and experience are not enough, because it depends on how fast we can absorb these good knowledge and experience. Because there are times where I know more about an area than the seniors" (Participant 4).

\section{Interpretation of the Analysis Results for}

\section{Each Theme with Adaptation}

Based on the results of data analysis, it was found that the experience of undergoing a transition period had.
Interpretation of Age Data Against Adaptation the largest percentage was $48 \%$ of adaptation

From the description of the results of analysis of demographic data according to age affect adaptation to the intention of new nurse turnover is 22 years old $(31,79 \%)$.

Interpretation of Data on Length of Employment on Transitional Experience

From the results of the demographic data analysis, the length of work affected the adaptation was at 7 months of work, it had an effect of $43,98 \%$ on the adaptation of new nurses.

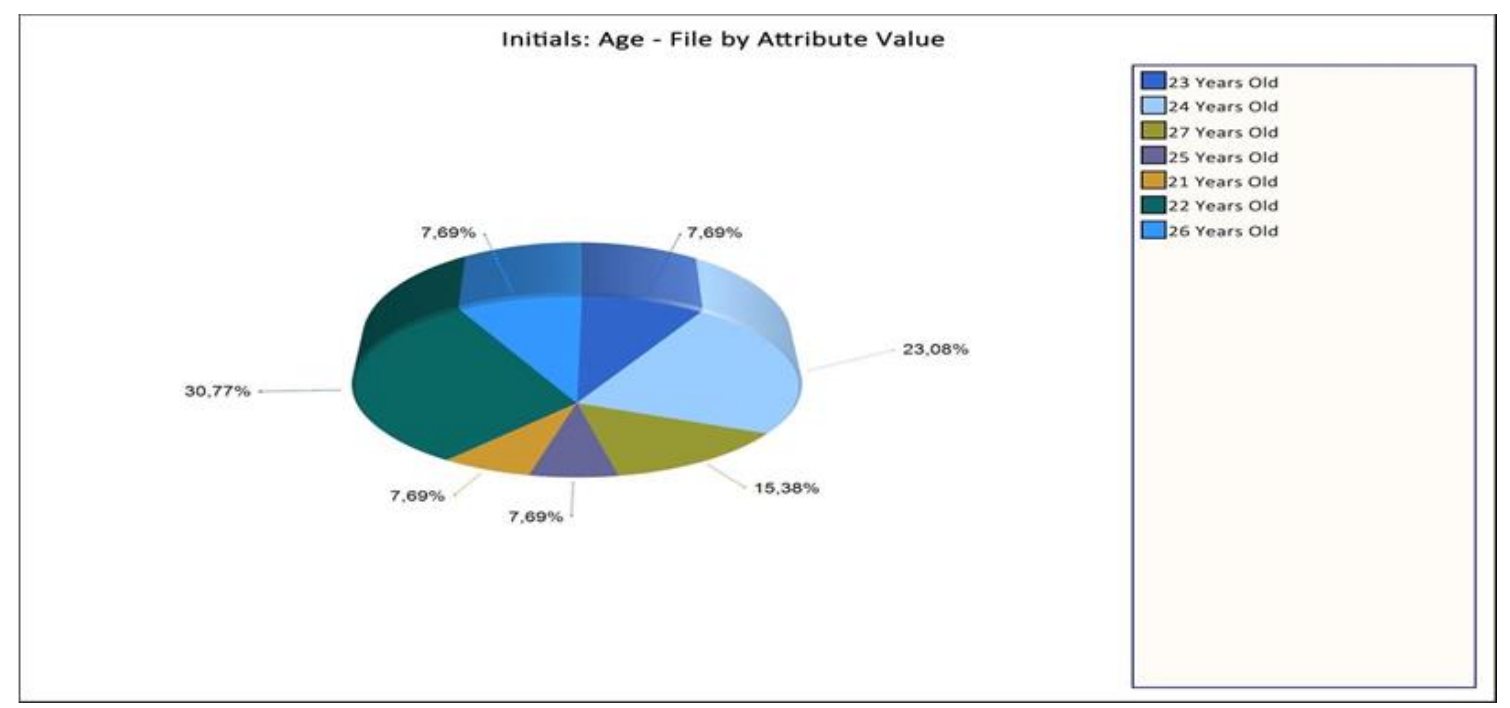

Fig. 1. Distribution of participants by age 


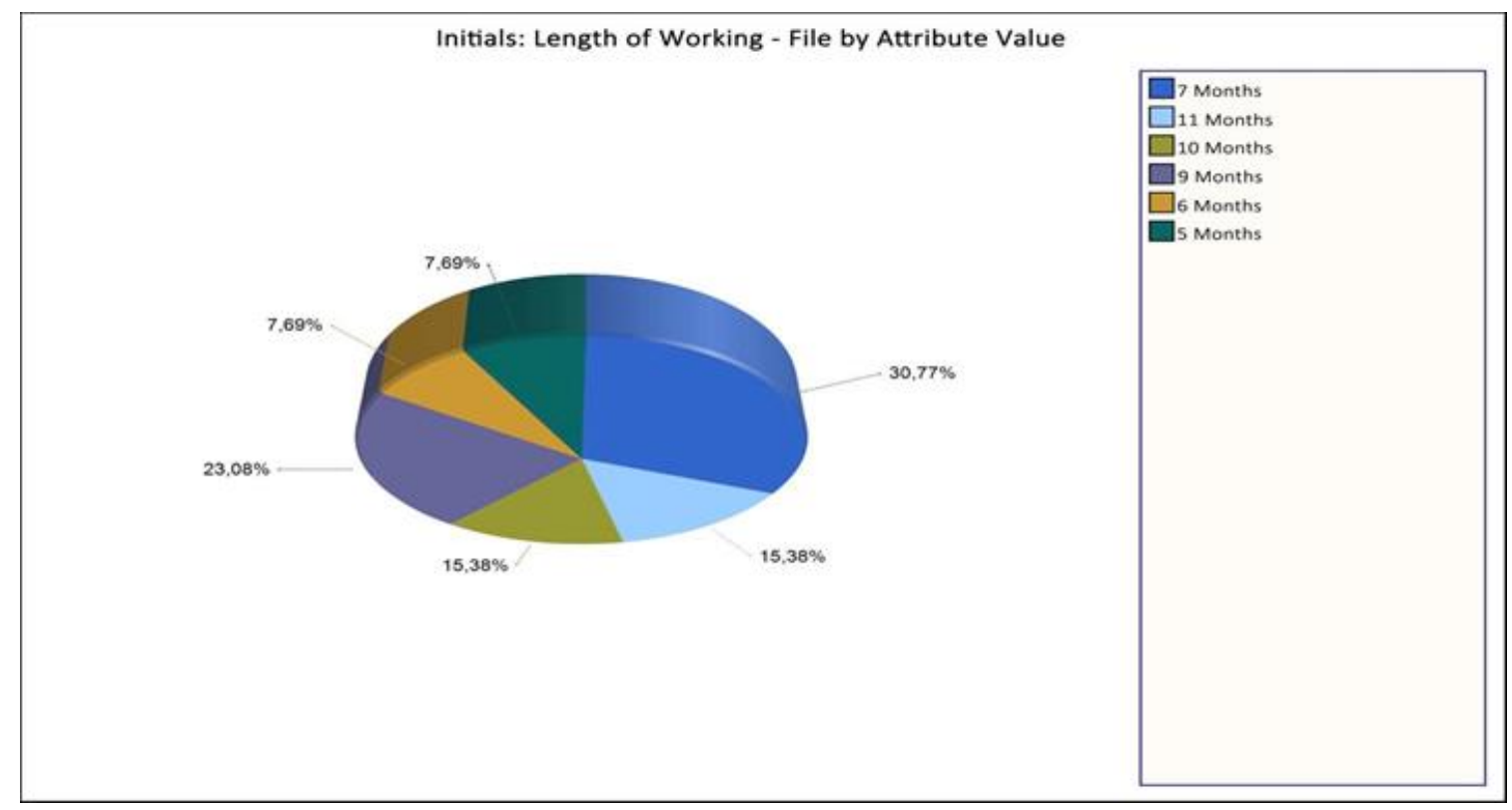

Fig. 2. Participants distribution based on length of work

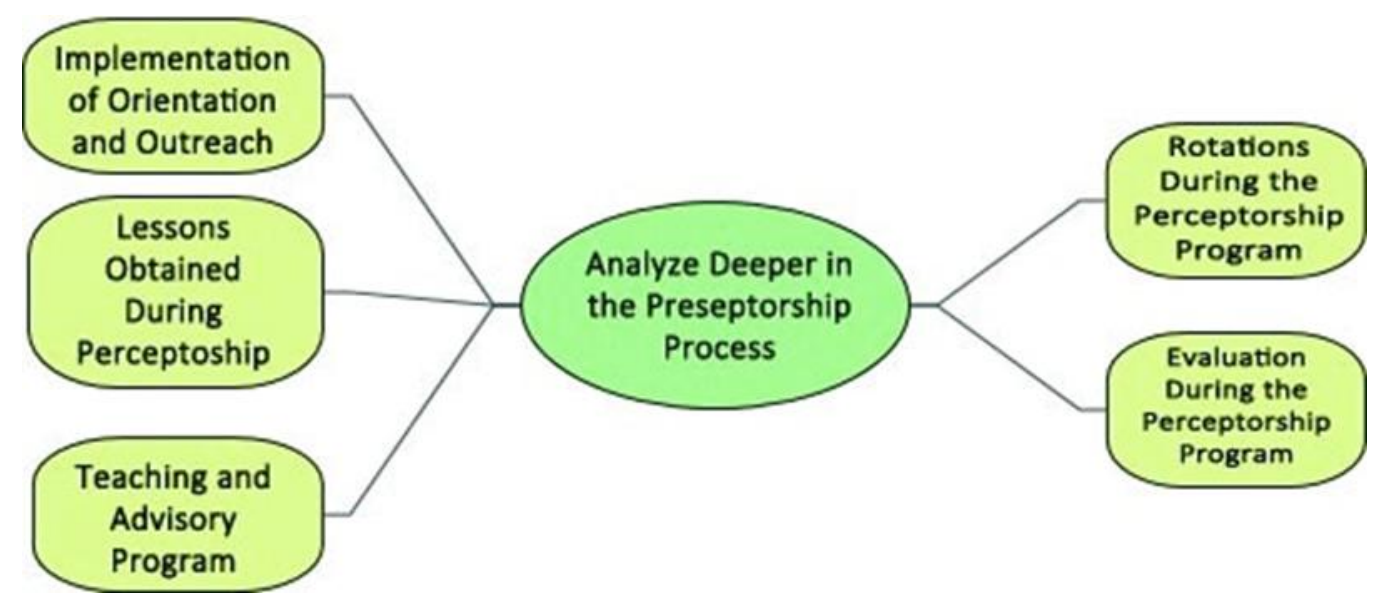

Fig. 3. Themes and sub themes of the preceptorship process 


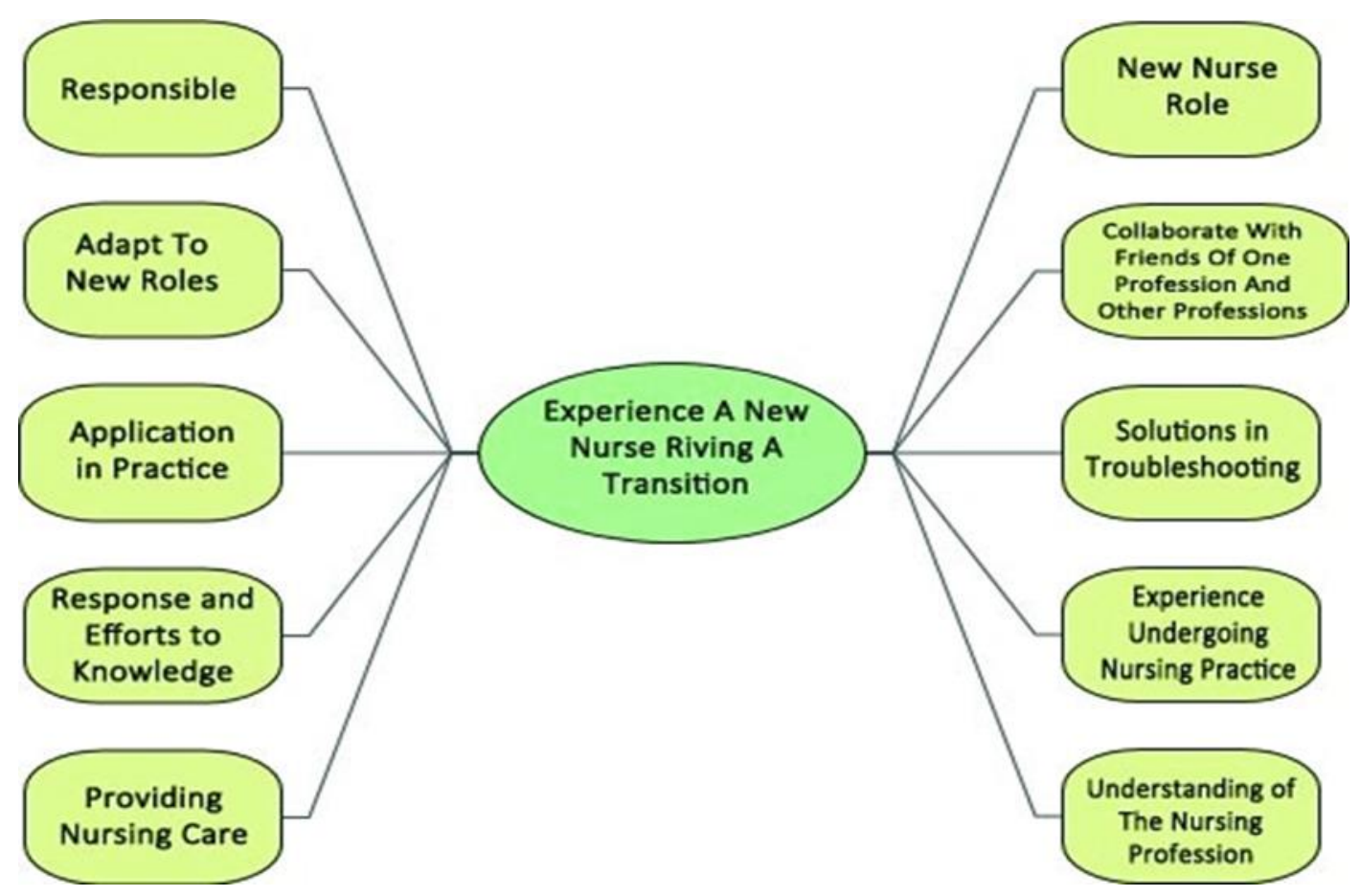

Fig. 4. Themes and sub-themes of experiences in transition

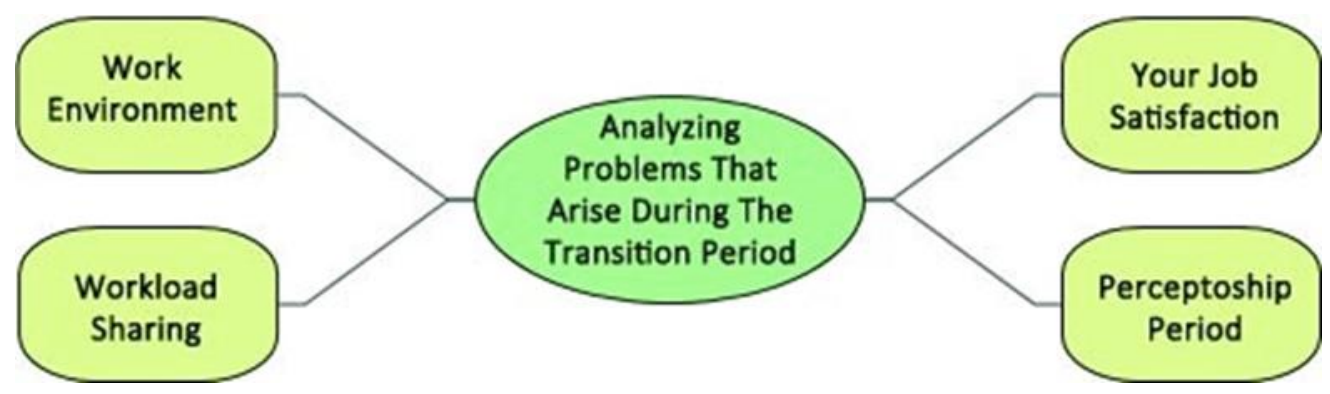

Fig. 5. Themes and sub-themes of problems arising during the transition period

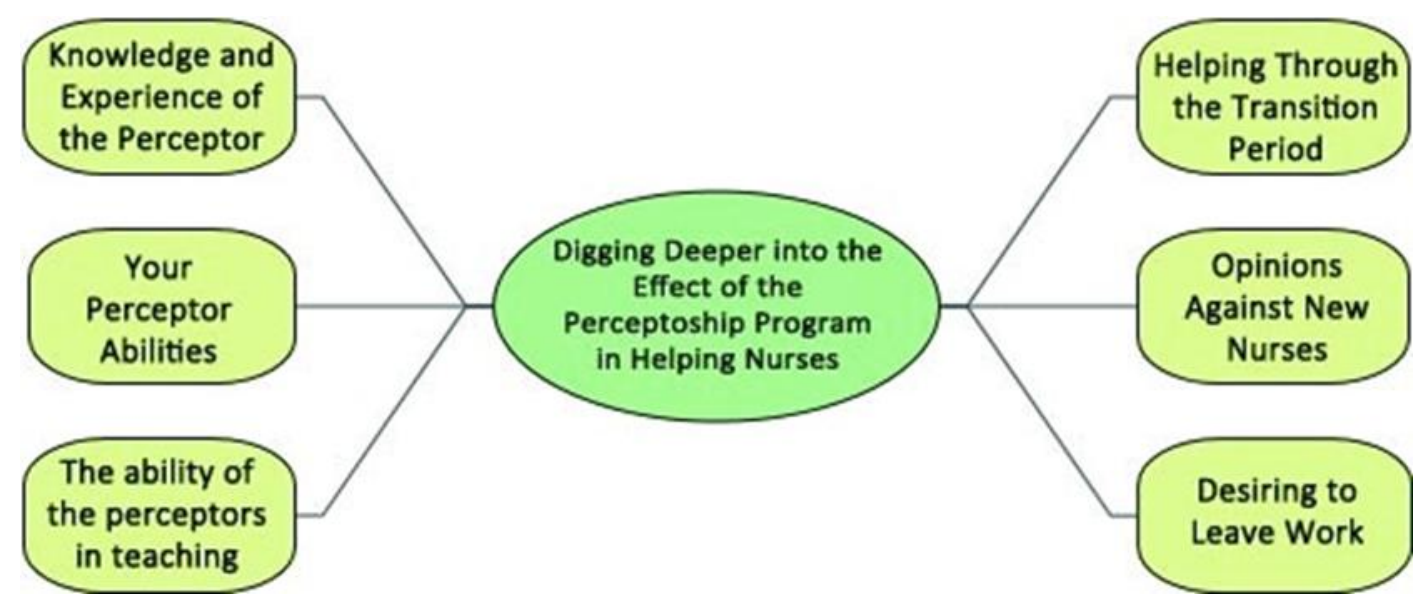

Fig. 6. Themes and sub-themes the influence of the preceptorship program 


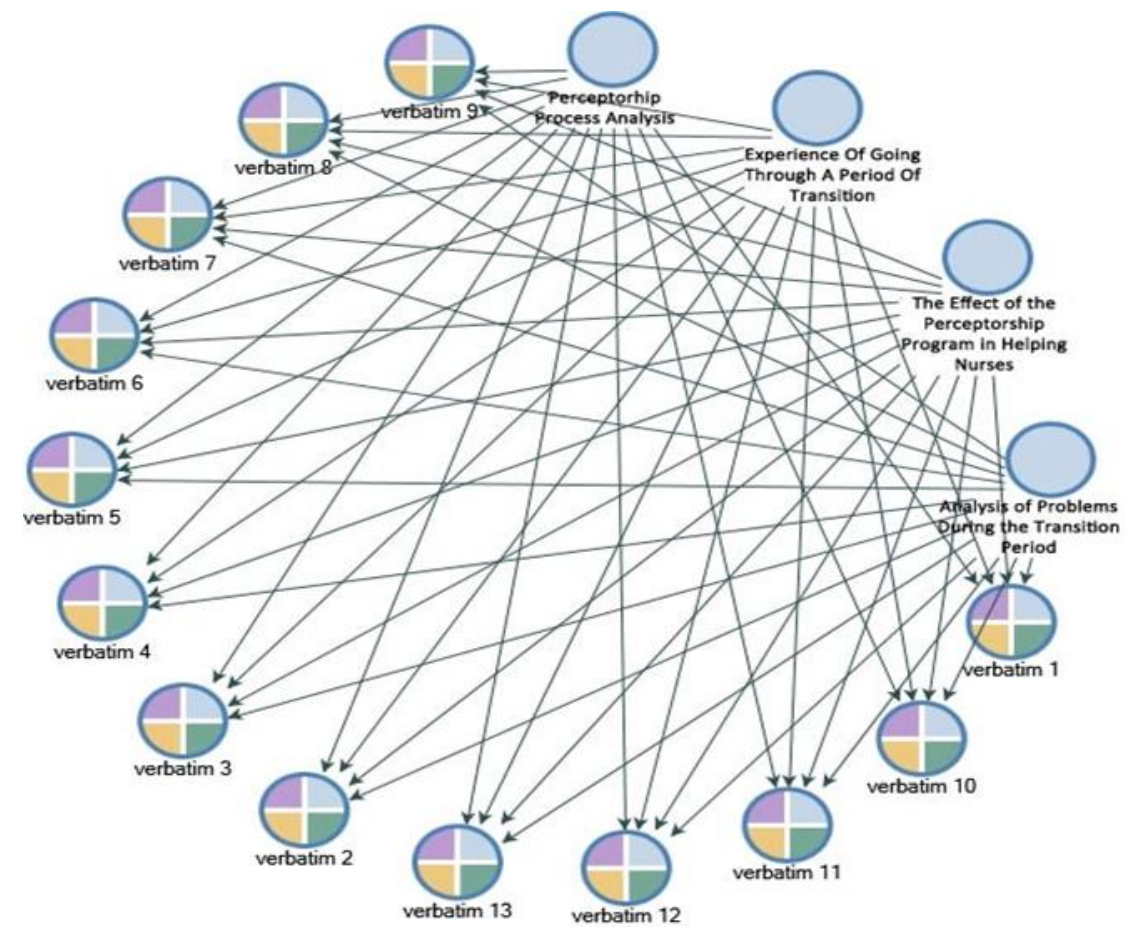

Fig. 7. Distribution scheme of participants' statements on transitional period sub-themes

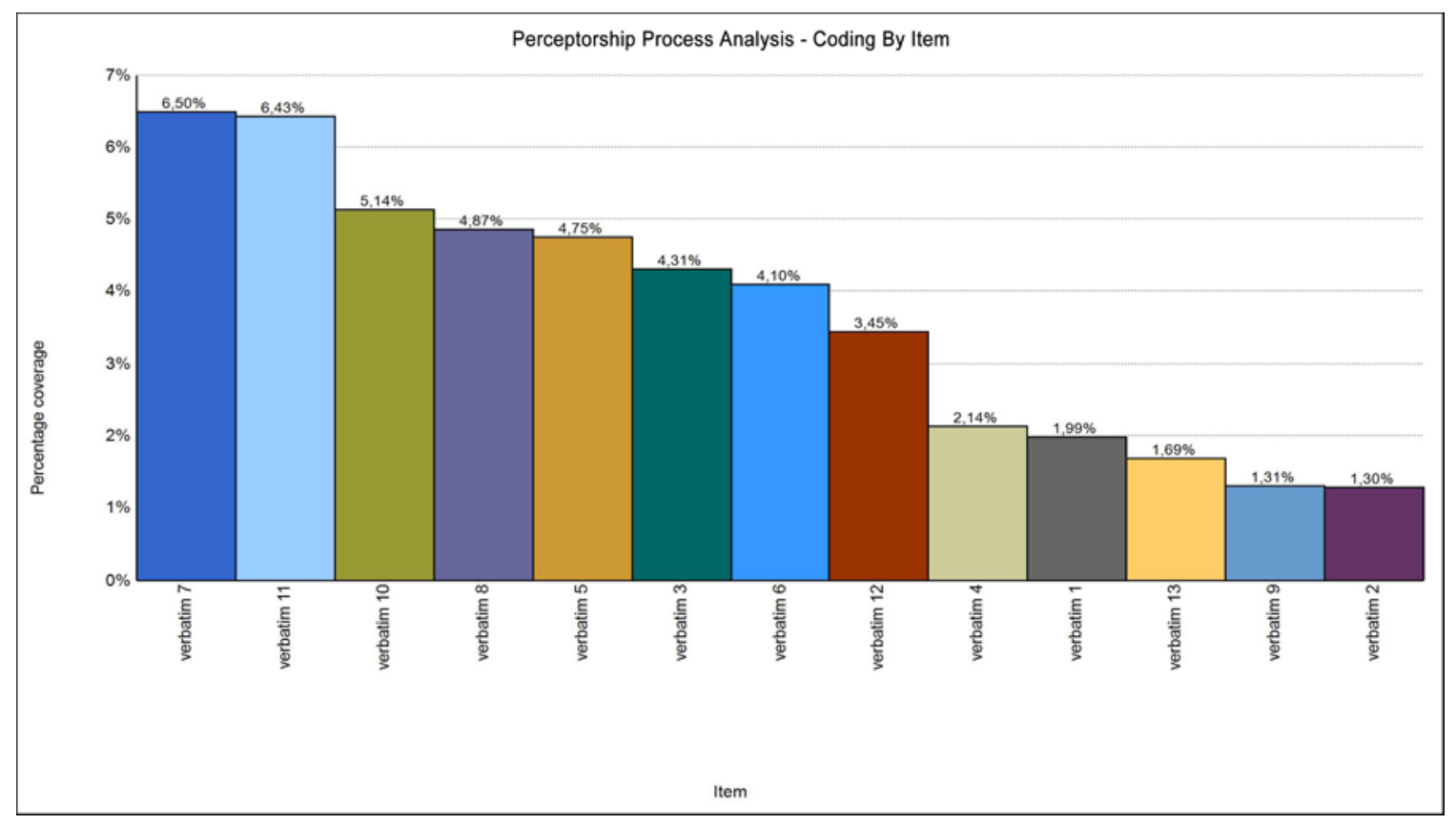

Fig. 8. Percentage showing the process for adaptation 


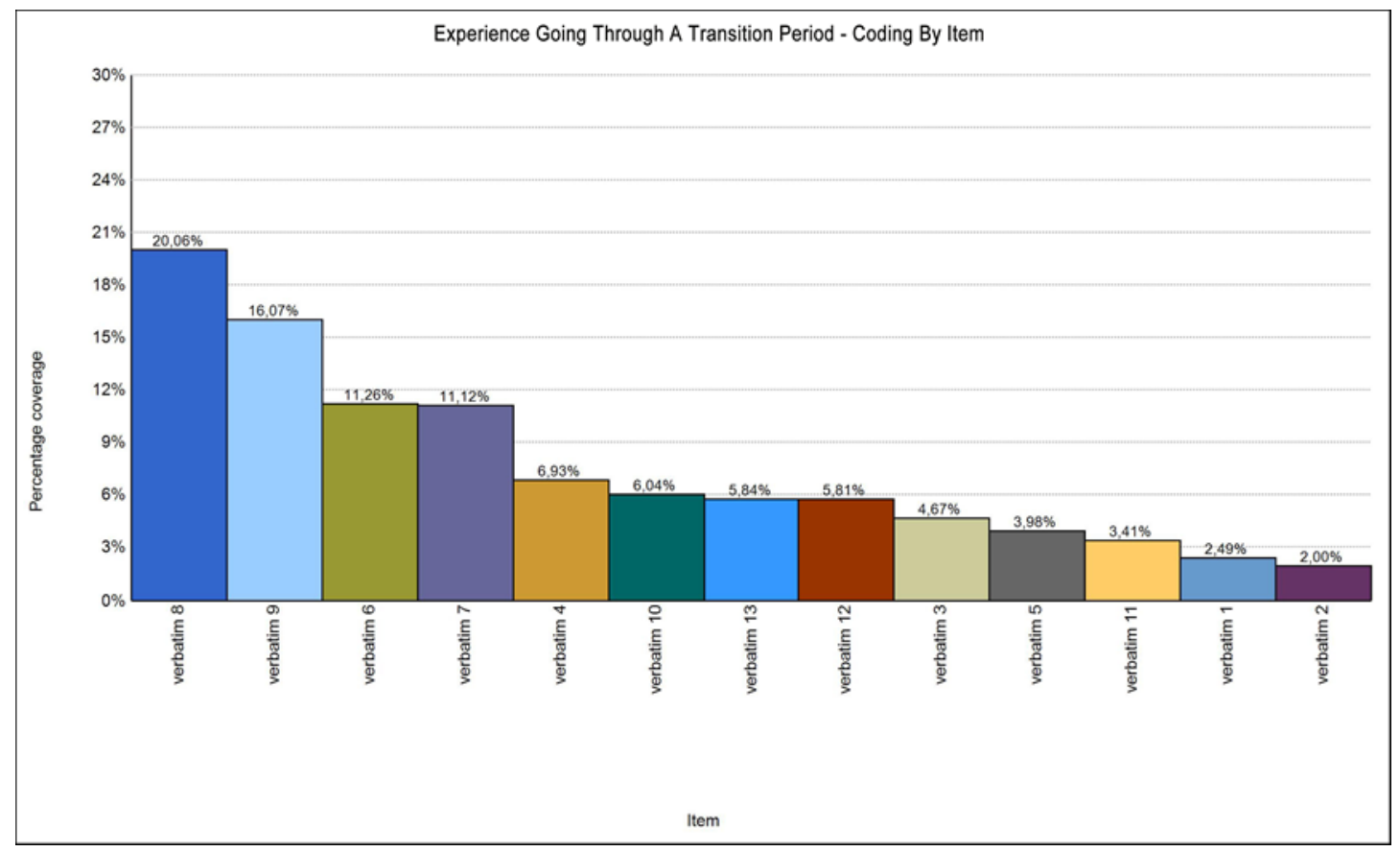

Fig. 9. Percentage showing the adaptive experiences during transition period

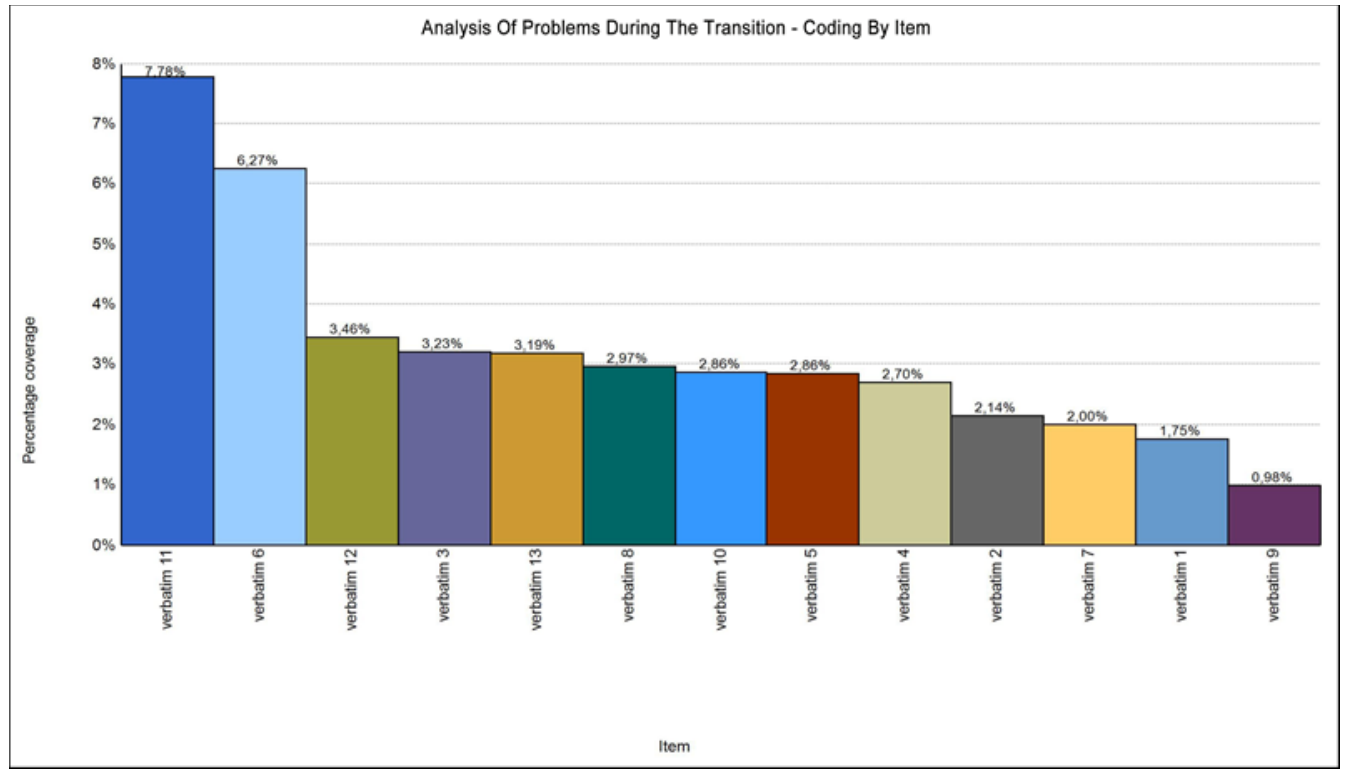

Fig. 10. Percentage of problems during the transition to adaptation 


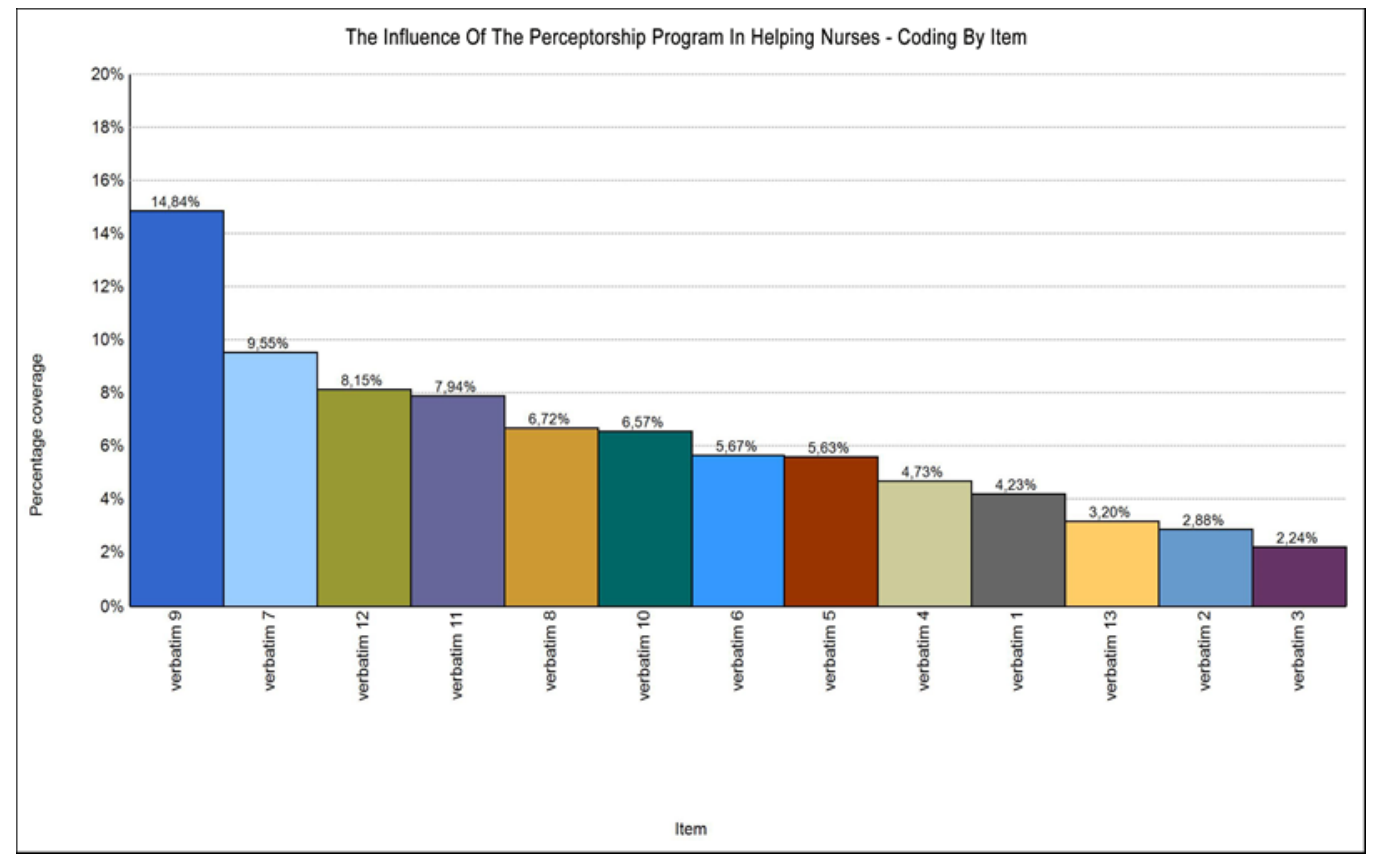

Fig. 11. Percentage showing the effect of the preceptorship program in assisting adaptation

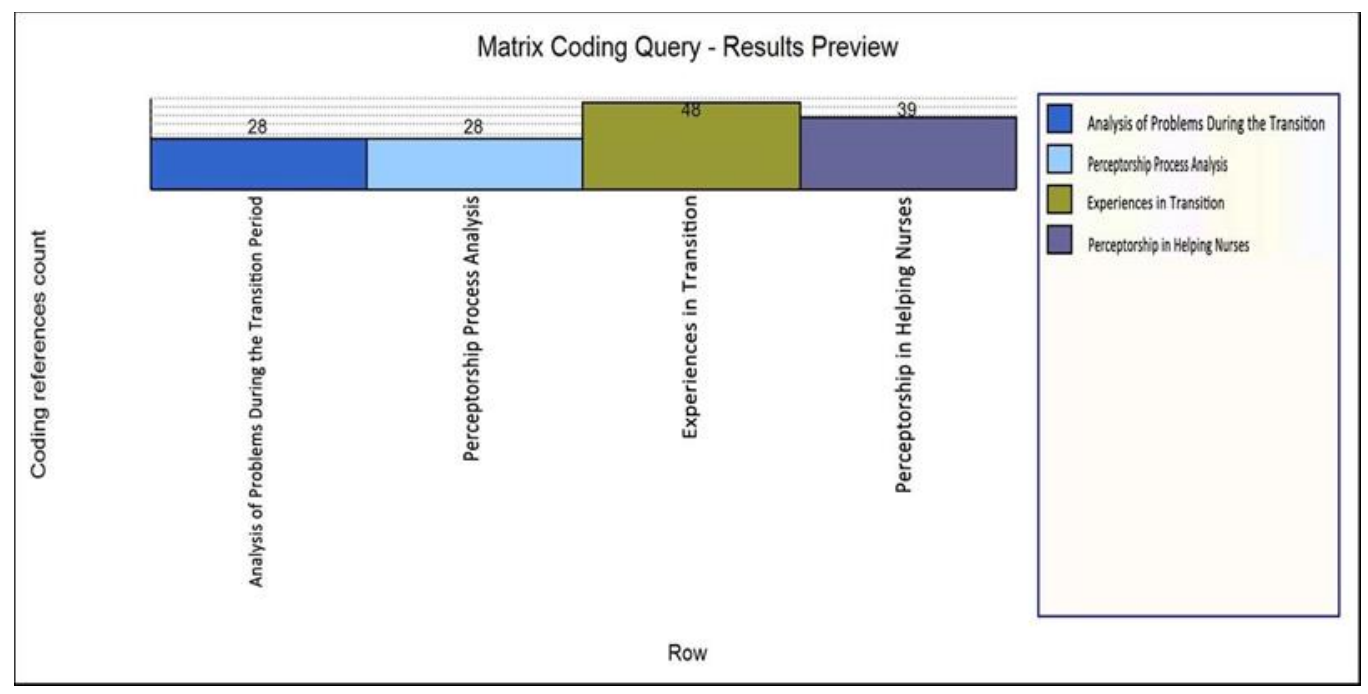

Fig. 12. Themes with adaptations 


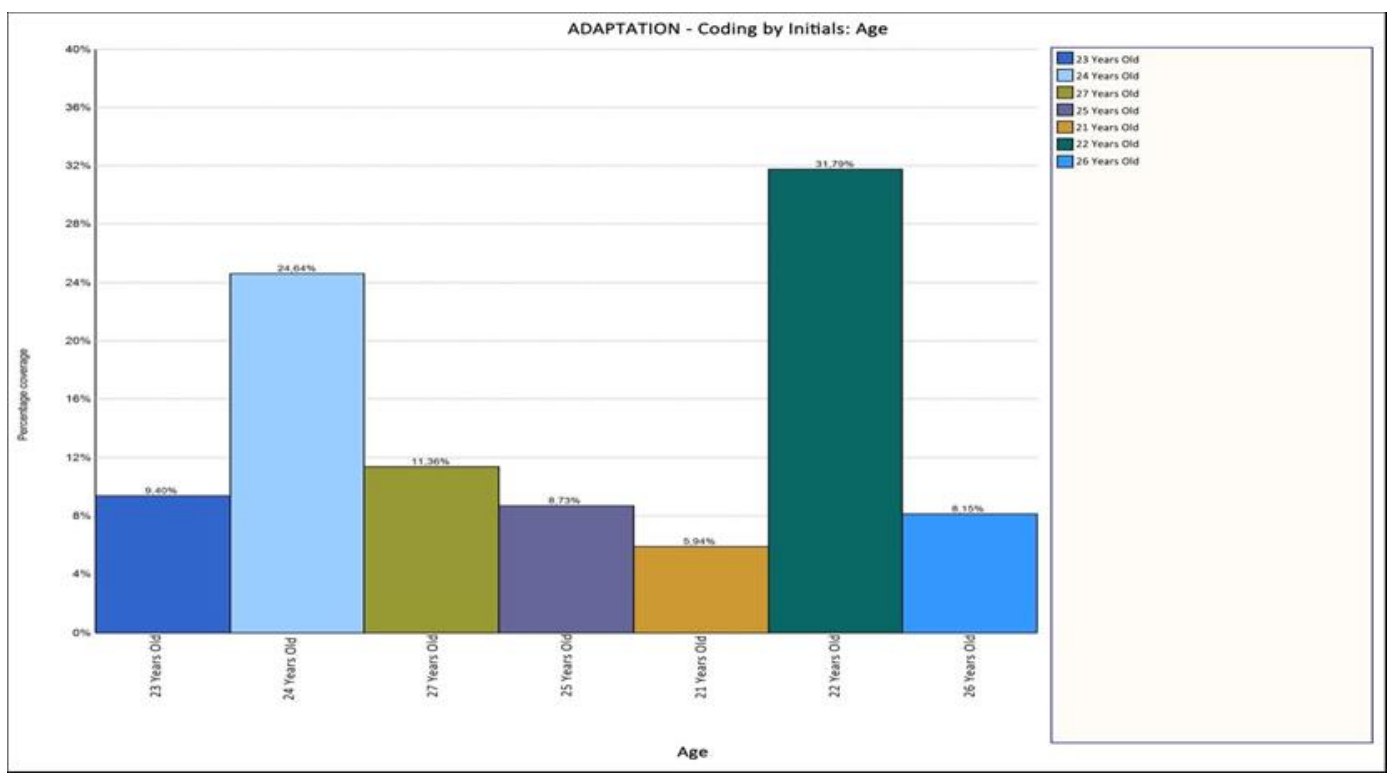

Fig. 13. Demographic description age affects adaptation

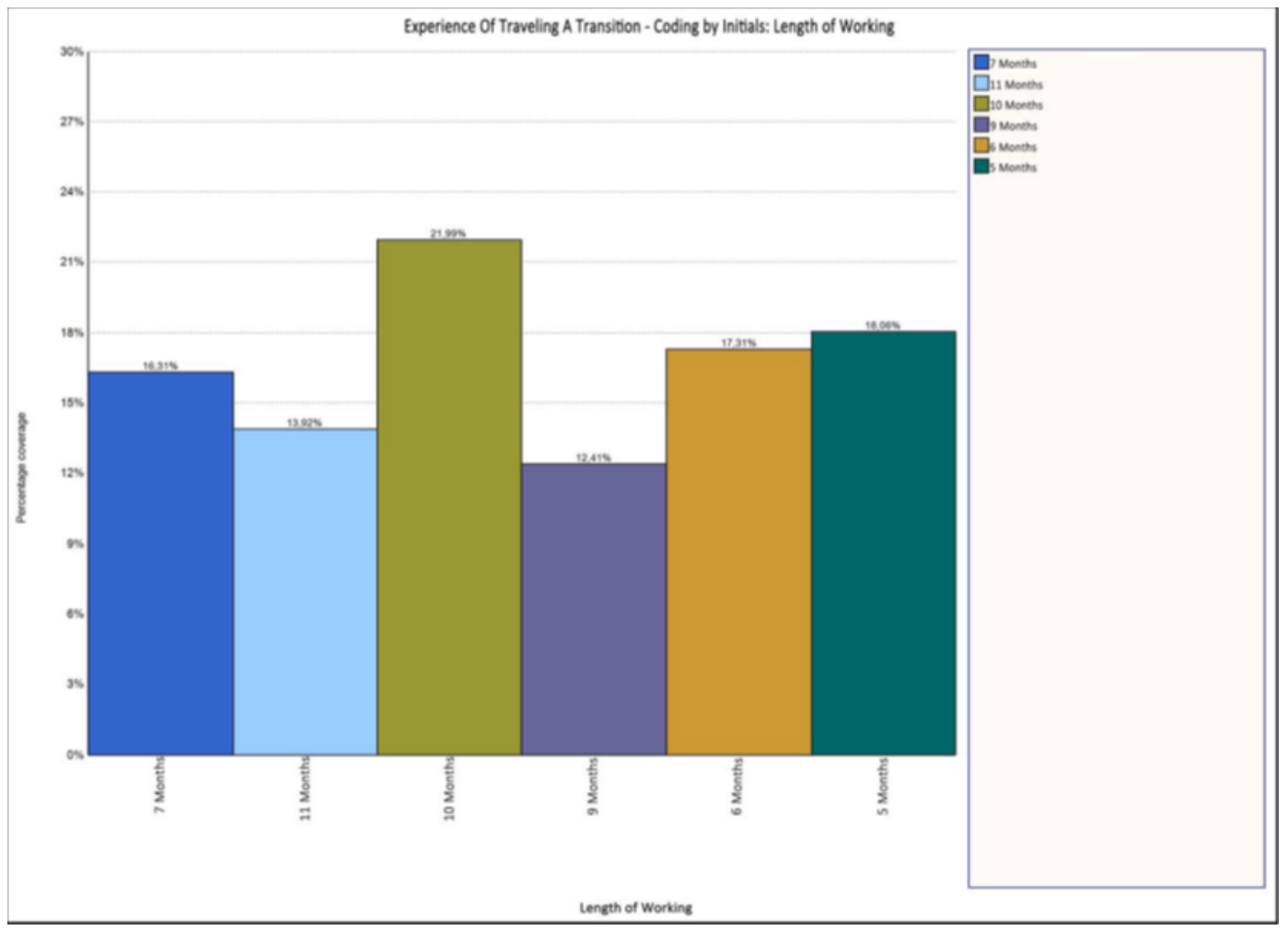

Fig. 14. Description of length of work affects transitional experience 


\section{DISCUSSION}

\section{Demographics}

From the results of this study, it was found that the new nurses who had the most desire to resign were nurses with a work period of 7 months, where the Duchscher model depicted that this period was in transition crisis. It can be said that these findings are in accordance with the theory presented by Duchscher's transitional stage model. Long. The first 4 - 8 months of work are at the stage of being and the 5- 7 months are the culmination of the difficulty of the 2nd stage of the transition along with the belief crisis.

This finding is possible because at this stage the new nurses' anxiety is at a moderate level (relative to transition shock), namely a state between insecurity and their competence in practicing nursing and fear of the consequences for patients, feeling less anxious with colleagues and anxious about themselves alone. Sofia Gusnia and Nurmaida Saragih (2013) in a study "The Relationship of Nurse Characteristics in the Preceptorship Program to the Adaptation Process for New Nurses" delivered results that were not much different, namely that the average length of work of new nurses that was not good enough in the adaptation process was 8-9 months [15]. The same results were obtained from research by Cheng et al, (2014) entitled "New Graduate Nurses' Clinical Competence, Clinical Stress, and Intention to Leave: A Longitudinal Study in Taiwan" that the intention to leave work occurred from the 3rd month to the month to 12 new nurses [4].

These results indicate that the longer a new nurse works, the more it prevents the nurse from adapting well. Beecroft, Dorey, and Wenten (2008), in their researches, said that the characteristics of nurses influenced whether the nurses left during the orientation period [16]. These characteristics include age, level of education, years of service. According to Cooper and Palmer (2000), gender also influences the preceptorship program and the adaptation process [17].

The demographic results based on age factors in this study were dominated by the age of 22 years old which is the youngest age among the participants as many as $30,7 \%$. This is in accordance with the opinion of Mobley (1986), where younger employees may have more opportunities to get new jobs and have smaller family responsibilities, thereby facilitating job mobility [18]. The same thing was also conveyed by Labraque et al. (2018), predicting that one of the most dominating turnover intentions is the age factor of nurses. Duchscher's transition model does not include age as a factor that can influence the transition period [19].

\section{The Experience of New Nurses Undergoing a Transitional Period}

There are four themes in this research, namely, problems during the transition period, the acceptability process, the experience of undergoing a transition period, and the influence of the preceptor program in helping nurses. Eight of the 13 participants stated that the experience of new nurses undergoing a transition period was the most pronounced statement.

The theme of the experience of new nurses undergoing a transition period contributed (48\%), which had the most influence on the adaptation process of new 
nurses, compared to the other three themes. The experience of new nurses during the transition period that is experienced includes, responsibility, adapting to new roles, implementing practices, responding and efforts to knowledge, providing nursing care, the role of new nurses, working with friends of one profession and other professions, solutions to experiencing problems, experience. Undergoing nursing practice, understanding of the nursing profession. This finding is in accordance with Duchscher who conveyed in the theory of transition shock that a new nurse is involved in a professional practice role, for the first time, is faced with various achievements and scope, intellectual and emotional.

The results obtained in this study illustrate that the experience of new nurses during the transition period of the first year is the most influential thing for new nurses to be able to adapt so that they wish to resign or survive. Duchscher's shock transition model has more detail distinguishing the stages of the one-year transition period into 3 stages. This opinion is in accordance with that expressed by Clipper and Cherry, (2015) that nurses who are working for the first time (fresh graduates) have difficulties during the transition from students to become professional practitioners and often experience a phenomenon known as shock during the transition period [9].

The final phase of the Duchscher is the Recovery Phase, which is a new nurse, equipped with skills, to successfully control her way through the shock phase to the recovery phase. There is a difference with this study, because it was found that new nurses who could not adapt to the transition period had a high intention to resign, namely $47.65 \%$, during the 9-11 months working period. These results illustrate that new nurses who already have 9-11 months of experience are still having difficulty adapting. This result is more in line with Phase Resolution, which is the last phase, namely the resolution of the Duchscher model whose impact can be positive or negative, where new nurses become confident and become competent practitioners or they show symptoms of fatigue and have the potential to leave their profession.

The results of this study are consistent with the assertion that practice transition experiences often lead to traumatic feelings during the first year, when new graduates enter the real world of health care [2]. So, the researcher sees the need for assistance throughout the first 1 year of new nurses so that the nurses have experience that enable them adapt to their new job.

\section{Program Preceptorship at HB Hospital and SMC Hospital}

All participants believed that the preceptor program was being undertaken at HB Hospital and SMC Hospital. The influence of the preceptor process, namely, the preceptor's knowledge and experience, the preceptor's ability, the preceptor's teaching ability, helping through the transition period, the opinion of new nurses and the desire to leave work influenced the adaptation process of new nurses by $28 \%$. The results of this study illustrate that more than $80 \%$ of new nurses think that the receptionist program is not very helpful in the transition process to adapt to 
new nurses. The results showed that the problems that arose during the transition process had an effect of $28 \%$ on the adaptation of nurses. Problems that arise during the transition process include work environment, division of workload, job satisfaction and implementation period of the preceptors, only as many as $0,98 \%-7,28 \%$, have an effect on the adaptation of new nurses.

Transition Shock, according to Duchscher, describes what new nurses have experienced during the year which are divided into several phases. The receptionist program was introduced to nursing in the UK in 1991 with the aim of increasing competence and self-confidence. According to Duchscher's transition theory, this occurs in the first phase of a new nurse, namely the first 0-3 months. This means that the preceptor program is a way for new nurses to be able to go through the transition period in the knowing phase according to Duchscher's theory [2].

\section{Preceptorship Program with Nurse} Turnover Intent at HB Hospital and SMC

\section{Hospital}

The shock factors during the transition period according to Duchscher's theory are those that affect the turnover of new nurses during the transition period. The results of this study are quite significant, illustrating that as many as $48 \%$, the experience of new nurses who are passing through the transition period, has followed the preceptor program and has an effect on new nurses to be able to adapt so that they wish to resign or not.
This result is inconsistent with the research "The effect of preceptorship on nurses' training and preparation with implications for Qatar" [20]. The study explaining that the preceptorship program is effective reduction in turnover rates. This could be due to the acceptability program being placed and the smaller number of fresh graduate nurse in the journal "From Transition Shock to Competent Practice" [9].

It is necessary to review the existing reception programs at both $\mathrm{HB}$ and SMC private hospitals so that they can be better structured so that the adaptation process for new nurses during the transition period can control the turnover of new nurses.

\section{CONCLUSION}

This study concludes that the experience of new nurses undergoing a transition period affects as many as $48 \%$ of new nurses in the transition period to adapt so that they want to leave work. The preceptor programs implemented at both HB and SMC Hospitals were only $2.24 \%-14,84 \%$ had an effect on the adaptation of new nurses to avoid turnover intention.

In data collection there were obstacles due to the Covid-19 outbreak, so that some who met the criteria for participants left without prior notification.

Determine 3 medical surgical inpatient units that have been prepared as a pilot for new nurses as expected by the hospital. The criteria for the preceptors and mentors nurses with at least 3 years of experience. Designing a new "Nurse transition adaptation" stages model in 3 stages: 0-3 month; orientation and preceptorship 
program, 4-8 month applying rules; profession understanding, the role and adaptation of new caregivers, role application of science in practice, solution to solve the problem and evaluation of difficulties and coping mechanism, 9-12 month task solution; responsibility, nursing and other professions collaboration, applying nursing care process, evaluation experience and coping mechanism. Further research is needed to determine the ideal work environment for nurses who are newly growing and successful in adapting through the transition period.

\section{REFERENCES}

[1] Kementerian Kesehatan Republik Indonesia, Peraturan Menteri Kesehatan Republik Indonesia Nomor 49 Tahun 2013 tentang Komite Keperawatan Rumah Sakit. Indonesia, 2013.

[2] M. Murray, D. Sundin, and V. Cope, “Benner's model and Duchscher's theory: Providing the framework for understanding new graduate nurses' transition to practice," Nurse Educ. Pract., vol. 34, pp. 199-203, Jan. 2019, doi: 10.1016/j.nepr.2018.12.003.

[3] C. Phillips, A. Kenny, and A. Esterman, "Supporting graduate nurse transition to practice through a quality assurance feedback loop," Nurse Educ. Pract., vol. 27, pp. 121-127, Nov. 2017, doi: 10.1016/j.nepr.2017.09.003.

[4] C.-Y. Cheng, H.-M. Tsai, C.-H. Chang, and S.-R. Liou, "New Graduate Nurses' Clinical Competence, Clinical Stress, and Intention to Leave: A Longitudinal Study in Taiwan," Sci. World J., vol. 2014, pp. 19, 2014, doi: 10.1155/2014/748389.

[5] J. E. B. Duchscher and L. Cowin, "Multigenerational Nurses in the Workplace," J. Nurs. Adm., vol. 34, no. 11, pp. 493-501, Nov. 2004, doi: 10.1097/00005110-200411000-00005.

[6] G. E. Chandler, "Succeeding in the First Year of Practice," J. Nurses Staff Dev., vol. 28, no. 3, pp. 103-107, 2012, doi: 10.1097/NND.0b013e31825514ee.
[7] H. Purwandari and W. A. Mulyono, "Permasalahan Mahasiswa pada Penempatan Praktik Ners Pertamakali di Stase Keperawatan Anak," Purwokerto, 2011.

[8] L. N. L. Yuniarti and T. Tutiany, "Implementation Study of Retention Programs and It's Impact on Turnover Intention Nurses in Hospital," Indones. J. Heal. Res., vol. 2, no. 2, pp. 39-48, Aug. 2019, doi: 10.32805/ijhr.2019.2.2.49.

[9] B. Clipper and B. Cherry, "From Transition Shock to Competent Practice: Developing Preceptors to Support New Nurse Transition," J. Contin. Educ. Nurs., vol. 46, no. 10 , pp. 448-454, Oct. 2015, doi: 10.3928/00220124-20150918-02.

[10] E. Wakefield, "Is your graduate nurse suffering from transition shock?," J. Perioper. Nurs., vol. 31, no. 1, Mar. 2018, doi: 10.26550/2209-1092.1024.

[11] G. Higgins, R. L. Spencer, and R. Kane, "A systematic review of the experiences and perceptions of the newly qualified nurse in the United Kingdom," Nurse Educ. Today, vol. 30, no. 6, pp. 499-508, Aug. 2010, doi: 10.1016/j.nedt.2009.10.017.

[12] K. Harrison-White and J. Simons, "Preceptorship: ensuring the best possible start for new nurses," Nurs. Child. Young People, vol. 25, no. 1, pp. 24-27, Feb. 2013, doi: 10.7748/ncyp2013.02.25.1.24.s9536.

[13] Nursalam, Metodologi Penelitian Ilmu Keperawatan: Pendekatan Praktis, 4th ed. Jakarta: Salemba Medika, 2014.

[14] S. Notoatmodjo, Metodologi Penelitian Kesehatan. Jakarta: Rineka Cipta, 2012.

[15] S. Gusnia and N. Saragih, "Hubungan Karakteristik Perawat dan Program Preceptorship terhadap Proses Adaptasi Perawat Baru," J. Keperawatan Padjadjaran, vol. 1, no. 1, pp. 10-17, 2013.

[16] P. C. Beecroft, F. Dorey, and M. Wenten, "Turnover intention in new graduate nurses: a multivariate analysis," J. Adv. Nurs., vol. 62, no. 1, pp. 41-52, Apr. 2008, doi: $10.1111 / \mathrm{j} .1365-$ 2648.2007.04570.x.

[17] A. M. Cooper and A. Palmer, Mentoring, Preceptorship and Clinical Supervision: A Guide to Professional Roles in Clinical 
Practice, 2nd ed. New Jersey: WileyBlackwell, 2000.

[18] W. H. Mobley, Pergantian Karyawan: Sebab-Akibat dan Pengendaliannya. Jakarta: Pustaka Binaman Pressindo, 1986.

[19] L. J. Labrague, D. M. McEnroe-Petitte, and K. Tsaras, "Predictors and outcomes of nurse professional autonomy: A cross- sectional study," Int. J. Nurs. Pract., vol. 25, no. 1, p. e12711, Feb. 2019, doi: 10.1111/ijn.12711.

[20] H. Arbabi, J. Johnson, and D. Forgrave, "The effect of preceptorship on nurses' training and preparation with implications for Qatar: A literature review," J. Nurs. Educ. Pract., vol. 8, no. 7, p. 44, Feb. 2018, doi: 10.5430/jnep.v8n7p44. 